\title{
THE SPEECH STYLES USED BY ERIN GRUWELL IN FREEDOM WRITERS MOVIE
}

\author{
Elma Ariella Setiawan, Esther Harijanti Kuntjara \\ English Department, Faculty of Letters, Petra Christian University, Surabaya, East Java, Indonesia \\ e-mail: ariella.elma@yahoo.com; estherk@petra.ac.id
}

\begin{abstract}
This study focused on the gendered speech styles namely; male speech styles and female speech styles used by Erin Gruwell in the Freedom Writers movie and the changes that can be perceived from her use of gendered speech styles. Based on the writer's descriptive qualitative approach analysis on the data, she found out that the teacher uses both male speech styles and female speech styles along 15 class scenes. She used Co-operative feature of female speech styles and Aggressive feature of male speech styles as her dominant feature which were used in each class scene. However, the writer could not find any gradual changes from the teacher's use of speech styles. Therefore, the teacher's changes in using speech styles did not seem to correlate with the students' changes in the attitude towards the teacher.
\end{abstract}

Keywords: Speech Styles, Male Speech Styles, Female Speech Styles

\section{INTRODUCTION}

Language is more than just a means which helps the speaker to deliver the information to the listener, but rather as an important key feature on leading people (Baxter, 2010). Therefore, a leader needs to be aware of the fact that their language products play important roles in influencing the audience's attitude towards them (Baxter, 2010). In the education context, teachers are considered as a leader by which their language product holds a very important role in the achievement of the students (Diaz and Rico, 2004).

According to Baxter (2010), men are naturally born as leaders, and women are their supporters or helpers. Since their natures are different, they would have different styles in speaking in order to achieve their own goal. Therefore, men have the tendency to be aggressive by speaking directly in order to take over the floor. On the other hand, because of women's role as a supporter, their goal is to build a good relationship which can be achieved by speaking co-operatively. Thus, speech styles can be divided into two features of speech styles based on gender, namely male speech styles and female speech styles. Yet, it does not necessarily mean that a woman cannot be a leader. In order to take over the lead, a woman with a higher position should have a good communication skill and be aware of how the language that she use can give an impact on how their employees will respond (Baxter, 2010).

In this present study, the writer chose to analyze the speech style of the female teacher in the movie Freedom Writers. This movie captures the true story of a teacher named Erin Gruwell who is dealing with 150 students of Woodrow Wilson High School who were unmotivated, unnoticed, and "unteachable" (Freedom Writers Foundation, n.d.). Some of them went to school because they were given an option whether they went to jail or studied at school as their penalty. Deep down inside Erin's students' misbehavior, they shared the same kind of trauma about racial discrimination.

In this study, the writer chose to focus on the gendered speech styles used by the teacher. The analysis of this study focused only on the interaction between teacher and students that happened in the 15 class scenes. Furthermore, the writer was intended to find the perceived meanings from the changes of the teacher's use of gendered speech styles.

In answering those questions, the writer used the theory of gendered speech styles developed by Baxter (2010). Gender implies the cultural construction of the society. On the other hand, as stated by Holmes (2001) and Trudgill (2000) in Baxter (2010) sex is the term used to imply the "biological characteristics such as the "male sex' and 'female sex". Therefore, the term gender and sex are distinguishable in the context of its preference. When people are discussing female speech styles, therefore, it does not necessarily refer to the woman. In other words, female speech style is referring 
to the speaker who has the cultural tendencies of being a woman. In their speaking, the female tends to be friendly while the male tends to be direct (Baxter, 2010). In the context of the workplace, usually, men are dominating the higher position, whereas, women tend to take a role as a supporting staff (Baxter, 2010).

However, the stereotype about the lower degree of women does not frustrate the chance of women to lead people. Supported by Baxter's (2010) theory, women can be a leader if they know the fact that language can influence people. Female may use or adapt the opposite gender speech styles features in their speaking in order to get the floor. They can adapt their speech based on the situation or the needs. Women can be an effective leader if they know how to adapt their speech style. As a teacher, a woman should know how to adapt their speech styles in order to be able to teach effectively. By doing so, the teacher can motivate the students to learn and to have a good achievement as the ultimate goal of being a leader in the classroom. They may use opposite gender speech styles which tend to be more aggressive in order to take the floor, yet maintain their female speech styles which tend to be friendly that can make them get closer to the students.

As quoted by Baxter (2010), Maltz and Borker (1982) identify three major goals of female speech styles namely: to build a relationship, to co-operate, and to express feelings. In line with Maltz's and Borker's (1982) theory, Baxter (2010) says that the three main goals expected by female speech styles users can be "achieved by a gendered speech style which is said to be personal, indirect, co-operative, expressive, and supportive" (Baxter, 2010, p. 58). In order to meet their goal, female speech styles users support their speaking style by using five features of female speech styles namely personal, compliant, polite, co-operative, and process-oriented (Baxter, 2010).

On the other hand, as it is stated by Baxter (2010), there are six features of male speech styles which have the tendencies to be competitive, adversarial, controlling, display, and task-driven (Baxter, 2010, p. 20). These implications aim to compete, to enhance authority, and to impress as cited by Baxter (2010) suggested by Maltz and Borker (1982). The six features of male speech styles are matter of fact, assertive, aggressive, use of humor, ego-enhancing, and goal-directed.

\section{METHODS}

This study was done by using the descriptive qualitative approach on the study of sociolinguistics. It was considered as a descriptive qualitative research because this study was conducted by looking at the fact in the society and analyzed by looking at the theory which has been applied in the particular area of study (Mukhtar, 2013). Therefore, the finding of this study was a descriptive opinion based on the result of the writer's analysis of the object which has been discussed and sorted systematically and continually by the academic advisor to prevent a biased result (Mukhtar, 2013).

In collecting the data, some steps had been done by the writer. First of all, the writer borrowed the original VCD (Video Compact Disc) of Freedom Writers movie from her university's movie collection in the library. Next, the writer searched the transcript of the movie from www.script-o-rama.com. While checking the teacher's utterances in the class scenes, the writer gave additional info about the teacher's gestures which was needed in doing the analysis in the future such as hedges, fillers, pauses, discourse markers, minimal response by adapting the symbol for transcription system suggested by van Lier (1988) and Johnson (1995) as cited by Walsh (2011) along side with the transcription system developed by Jefferson (1978) as cited in Woofit (2005). This feature of transcription system was very useful for the data analysis of the writer since in some characteristics of both features of female and male speech styles are non-verbal.

After completing the transcript, the writer gave the number for each utterance of each class scene. Later, she sorted out the teacher's utterances that could be used as the data for analysis. The teacher's utterances which do not contain the gendered speech styles will be discarded. After sorting out the data for the analysis, the writer continued the next step with her analysis on the data.

\section{ANALYSIS AND FINDINGS}

In doing the analysis for this study, the writer found the features and frequencies of male speech styles and female speech styles used by Erin Gruwell and the changes of her use of gendered speech styles in every class scene in the movie which can be seen in the summary table below. 
Table 1: The Male and Female Speech Styles Used by Erin Gruwell

\begin{tabular}{|c|c|c|c|c|c|c|c|c|c|c|c|c|c|c|c|}
\hline \multirow{4}{*}{$\begin{array}{c}\text { Class } \\
\text { Scene } \\
1\end{array}$} & \multicolumn{6}{|c|}{ Male Speech Styles } & \multicolumn{4}{|c|}{ Total } & \multicolumn{5}{|c|}{$\begin{array}{c}\text { Female Speech } \\
\text { Styles }\end{array}$} \\
\hline & \multirow{2}{*}{$\begin{array}{c}\mathrm{M} \\
\mathrm{a} \\
\mathrm{t} \\
\end{array}$} & \multirow{2}{*}{$\begin{array}{l}\mathrm{A} \\
\mathrm{s} \\
\mathrm{s} \\
\end{array}$} & \multirow{2}{*}{$\begin{array}{l}\mathrm{A} \\
\mathrm{g} \\
\mathrm{g}\end{array}$} & \multirow{2}{*}{$\begin{array}{l}\mathrm{U} \\
\mathrm{o} \\
\mathrm{h} \\
\end{array}$} & \multirow{2}{*}{$\begin{array}{l}\mathrm{E} \\
\mathrm{g} \\
\mathrm{O}\end{array}$} & \multirow[t]{2}{*}{$\begin{array}{c}\mathrm{G} \\
\text { oa }\end{array}$} & \multicolumn{2}{|c|}{ MSS } & \multicolumn{2}{|c|}{ FSS } & \multirow{3}{*}{$\begin{array}{l}\mathrm{P} \\
\mathrm{e} \\
\mathrm{r} \\
3\end{array}$} & \multirow{3}{*}{$\begin{array}{l}\mathrm{C} \\
\mathrm{o} \\
\mathrm{m} \\
3\end{array}$} & \multirow{3}{*}{$\begin{array}{l}\mathrm{P} \\
\mathrm{o} \\
1\end{array}$} & \multirow{3}{*}{$\begin{array}{l}\mathrm{C} \\
\mathrm{o} \\
1 \\
1\end{array}$} & \multirow[t]{3}{*}{$\begin{array}{c}\mathrm{Pr} \\
\mathrm{O}\end{array}$} \\
\hline & & & & & & & & & & & & & & & \\
\hline & 4 & 4 & 4 & & & 2 & 14 & $45 \%$ & $55 \%$ & 17 & & & & & \\
\hline 2 & 2 & 5 & 2 & 1 & & 1 & 11 & $73 \%$ & $27 \%$ & 4 & 1 & 1 & & 2 & \\
\hline 3 & 4 & 8 & 5 & & 1 & 2 & 20 & $57 \%$ & $43 \%$ & 15 & & 2 & 1 & 1 & 2 \\
\hline 4 & & & 1 & & & & 1 & $33 \%$ & $67 \%$ & 2 & & & & 1 & 1 \\
\hline 5 & $\begin{array}{l}1 \\
4\end{array}$ & $\begin{array}{l}1 \\
6\end{array}$ & $\begin{array}{l}1 \\
3\end{array}$ & & 3 & 5 & 51 & $46 \%$ & $54 \%$ & 59 & $\begin{array}{l}1 \\
4\end{array}$ & 8 & & $\begin{array}{l}2 \\
7\end{array}$ & $\begin{array}{l}1 \\
0\end{array}$ \\
\hline 6 & 9 & 7 & 7 & & 3 & 2 & 28 & $58 \%$ & $42 \%$ & 20 & 7 & 3 & & 8 & 2 \\
\hline 7 & & 1 & 1 & & & 1 & 3 & $60 \%$ & $40 \%$ & 2 & & & & 1 & 1 \\
\hline 8 & 3 & 5 & 2 & & 2 & 2 & 14 & $52 \%$ & $48 \%$ & 13 & 2 & & 1 & 9 & 1 \\
\hline 9 & 1 & 1 & & & & & 2 & $33 \%$ & $67 \%$ & 4 & & 1 & & 3 & \\
\hline 10 & & 1 & 1 & & 1 & & 3 & $75 \%$ & $25 \%$ & 1 & & & & 1 & \\
\hline 11 & 1 & 1 & 3 & & 1 & & 6 & $60 \%$ & $40 \%$ & 4 & & & & 4 & \\
\hline 12 & 2 & 4 & 2 & & & 2 & 10 & $53 \%$ & $47 \%$ & 9 & 1 & 2 & 4 & 2 & \\
\hline 13 & & & 1 & & & & 1 & $33 \%$ & $67 \%$ & 2 & 1 & & & 1 & \\
\hline 14 & 5 & 1 & 2 & & & & 8 & $40 \%$ & $60 \%$ & 12 & 2 & 2 & & 8 & \\
\hline 15 & 3 & 4 & 2 & & & 3 & 12 & $67 \%$ & $33 \%$ & 6 & 1 & & & 4 & 1 \\
\hline
\end{tabular}

From the summary table above, the writer tried to analyze the cause of the changes of the use of both male speech styles and female speech styles. This was done by looking at the topic discussion and situation in each class scene. In the first class scene, the percentage of female speech styles are higher. It is quite natural to do so since it was the first meeting between the teacher and the students. She needed to give a good first impression to the students and build a good relationship with them. Therefore, the teacher mostly used Co-operative feature from female speech styles in order to get closer to them. Here is the example from class scene 1:

Example:

\subsection{Is that correct? ((eye contact)) ((head-nodding))}

In this utterance, the teacher showed her Co-operative feature of female speech styles by asking question to make sure whether she pronounce her student's name correctly or not. She was also giving an eye contact, and head nodding which are the characteristics of Co-operative feature. At the end of the class, two students in the class, Jamal and Andre started a fight. The teacher tried to stop them by interrupting them, but she failed. In her attempt to stop them, she used Assertive feature to interrupt them and take over the control. Later, she asked a help from the security guard to stop them and prevent any worse situation. Here is the example of the teacher's utterance:

Example:

\subsection{3 [Please sit back in your seats]}

In this utterance, the teacher used Assertive feature by interrupting the confrontation between the students in order to take over the control in the classroom.

However, in the class scene 6 , where the students started to obey, the teacher used male speech styles more. The use of male speech styles is raised to $58 \%$. The writer saw that the students started to obey the teacher's order. It can be seen since the students decided to play the game and follow the rules. At the end of the class, when the teacher asked them to come and take a book for daily journal, all of the students came and took the book. It shows the positive changes in their attitude towards the teacher compared to the first class scene where they did not pay attention to her, mocked her, and even left the class.

In this class scene, the teacher asked them to play a game named Line Game. In this game, the teacher asked a question and if the question applied to them, they needed to step on the line. After 
that, they needed to step back and be ready for the next question. She aimed to get closer to them by collecting information about them and open their mindset about each other. She wanted to show that despite their different ethnicity, they have the same feeling and bad experience over gang violence. Therefore, the teacher used Aggressive feature quite a lot by using a verb of action and violence as follow:

Example:

6.14 Stay on the line if you've lost more than one friend.

The teacher gave an aggravated directive from Assertive feature to the students to stay on the line if they have lost more than one friend. In her order, she used a verb of action: stay from aggressive feature. In asking the questions, the teacher used Personal feature by adding some pauses, and giving a scene setting from Process-oriented feature about how the game will be done. Here are the examples of the teacher's use:

Example 1:

6.8 How many of you know ... where to get drugs right now?

The teacher was asking a question which is quite sensitive. Therefore, she hesitated and gave a pause which shows her use of Personal feature of female speech styles.

Example 2:

6.1 We're gonna play a game, all right? ... It's a lot of fun. I promise ... Look, you can either sit in your seats reading those workbooks, or you can play a game ... Either way, you're in here till the bell rings.

Okay. This is called the Line Game. ((smiling)) I'm gonna ask you a question. If that question applies to you, you step onto the line, and then step back away for the next question ... Easy, right?

In this class scene, she gave a scene setting of how the game works from Process-oriented feature. Meanwhile, in class scene 14, one of her students, Tito asked if she was going to teach Junior class in the next year and stay with them. The teacher answered that she would not be able to be with them next year because the regulation did not allow a new teacher to teach Junior class. In expressing her feelings that she wanted to stay with them, the teacher used Personal feature from female speech styles as follow:

Example:

\subsection{Of course I do. I can't.}

The teacher expressed her feelings by agreeing the students' statement that she wanted to stay with them. Using an expressive feeling is categorized as Personal feature of female speech styles. Later, the whole class was shouting out their idea about how to make her stay and teach the Junior class. The teacher responded to her students by declaring and emphasizing the fact that she could not teach Junior class.

Example:

\subsection{I'm not allowed to teach junior and seniors ((smiling))}

The teacher said the reason directly to the class that she is not allowed to teach junior and senior year. This sentence is categorized as a declarative from Assertive feature. At the same time, this is based on the fact of Matter of fact feature of male speech styles. In stating the fact, the teacher used one verb of action "teach" which is one of the characteristics of Aggressive feature of male speech styles. Therefore, it can be seen that the teacher used both male speech styles and female speech styles in the last scenes where the students had been closer to the teacher and change their attitude towards her. The students even asked her to stay with them for the next year of Junior class. It seemed that the students had built a bond of feelings with the teacher.

Based on the writer analysis, on Erin Gruwell's use of male speech styles, she used Aggressive feature in almost every class scene. She used one characteristic from Aggressive feature which is the use of verb of action. In her directives, whether they were softened or not, there must be a verb of action there. She also called her students by their name in a higher intonation which can be categorized as a name-calling. The teacher also used Matter of fact feature more than Egoenhancing feature. This might be interpreted because she did not want to be looked as she was judging them. In the Matter of fact, the teacher would use a real example in the society that had happened in the past. For example, when she told a story about how Holocaust happened, rather than gave a story about what happened in their society at that time. If she used the example of what 
happened in their society, she would use Ego-enhancing feature by referring to what they had done and who they knew. It would be sound as if she judged what they did.

However, in her use of female speech styles, the teacher might be hesitating in talking about sensitive topics, such as racism, gang, and violence. Therefore, she added some pauses in her speech to show her Personal feature. This might be because she did not want to be too aggressive because it might hurt them or make them feel annoyed. She also used a modal auxiliary verb from Compliant feature in order to soften her directives because she did not want to dominate the class. From the writer's point of view, the teacher seemed to know when to use a softened speech and when to take over the control and the floor.

Finally, the writer came to a conclusion that the use of male speech styles and female speech styles depends on the classroom context. The teacher used both male speech styles and female speech styles in since the beginning until the end. The writer interpreted that the teacher used both speech styles based on her need and the situation in the class. For example, in the first class scene the teacher used more female speech styles because it was their first meeting, she aimed to build a good relationship with them by giving a good first impression. Meanwhile, in the sixth class scene, the teacher used more male speech styles since she aimed to start to control the topic of discussion in the class. Therefore, she needed to gain more attention and take over the control of the classroom, particularly by using male speech styles, especially the Assertive and Goal-directed feature. However, in her attempt to control the classroom, the teacher also used Personal feature of female speech styles when she hesitated in talking about the racial and gang issue which is very sensitive topics among the classroom. The teacher would use Compliant feature in order to soften her directives and avoid any confrontation from the students by using an auxiliary verb. In the class scene 14, where the students showed their positive changes in attitude towards the teacher, the teacher still using both male speech styles and female speech styles. The teacher used Personal feature of female speech styles and Assertive, Matter of fact, and Aggressive feature of male speech styles at the same time. Therefore, it can be seen that the teacher maintained her use of both male speech styles and female speech styles until the last class scenes where the students have shown their changes in attitude towards the teacher.

The writer interpreted that the insignificant changes was caused by what happened in class scene 5, one of her student, Eva said that she hated her because she was white. The whole class had a mindset that white people always wanted to be respected. As a result, the teacher tried to break the stereotype about white people by trying to soften her speech and degrade herself as a teacher. She avoided using male speech styles which tend to be stronger. She wanted to be treated as a friend by her students. By doing so, the students would not be burdened by the status or the race of the teacher.

In Erin Gruwell's attempt to break their stereotype, she used Co-operative feature of female speech styles in every class scene. As a result, Co-operative feature became the most frequently used feature of female speech styles. She was not only gave eye contacts and smiles, but also used both personal and inclusive pronoun in every utterance to show her use of Co-operative feature. Another characteristic of Co-operative feature might be seen by teacher's gestures such as eye contact, headnodding, and smile. In this movie, the writer found that in several utterances of each class scene, the teacher gave an eye contact, smile and even a head-nodding. For example, the teacher smiled and gave an eye contact when she was greeting her students. She also gave an eye contact toward her student when she is referring to one student of hers. The teacher also did a head-nodding when she was agreeing the students' opinion like in the class scene 5 (utterance 5.14). It happened when the teacher agreeing the students' opinion about the fact how every ethnicity hated each other.

\section{CONCLUSION}

From the data analysis of this study, the writer found that Erin Gruwell used all features of male speech styles. However, she used Use of Humor feature only once in class scene 2. The most frequently used feature of male speech styles is Aggressive feature. Erin Gruwell used Aggressive feature all along the 14 of 15 class scene. The teacher also used Matter of fact feature more often than Ego-enhancing feature in her utterances. The writer interpreted that the teacher tended to give an example which was based on actual facts or histories rather than what the students had done in 
order to avoid any confrontation or misunderstanding. It was also done so that the students would not feel like they were being judged.

Erin Gruwell also used all features of female speech styles. Although she used Polite feature the least. She maintained her Personal feature by giving pauses when she was talking about sensitive topics, such as races, gangs, and violence due to gang affiliation. The teacher used Co-operative feature as her most dominant feature of female speech styles which was used along 15 class scenes of the movie. The writer interpreted that the teacher aimed to break down the age gap between her students and her. She did not want to be treated as a teacher. The reason was because the whole class had a stereotype that white people always want to be respected and seen as a superior. Therefore, the teacher aimed to avoid any confrontation about races by breaking down the stereotype by maintaining her Co-operative feature.

Finally, since there were no gradual changes in the use of speech styles, the writer came to conclusion that Erin Gruwell's tendency in using male speech styles and female speech styles did not seem to correlate with the changes on students' response and attitude towards her. Therefore, the writer hopes that the findings of this study inspire the reader to conduct a further study on the element in the classroom which enhances the change in students' attitudes and response besides the teacher's speech styles.

\section{REFERENCES}

Baxter, J. (2010). The language of female leadership. London: Palgrave Macmillan

Diaz \& Rico, Lynne T. (2004). Teaching English learners strategies and methods. San Bernardino: Pearson.

Eckert, P. (2000). Linguistic variation as social practice. Oxford: Blackwell.

Freedom Writers Foundation. (n.d.) Retrieved from http://www.freedomwritersfoundation.org/about.html

Holmes, J. (2001). An introduction to sociolinguistics. Longman: New York.

Internet Movie Database. (n.d.). Freedom writers. Retrieved from http://www.imdb.com/title/tt0463998/

Mukhtar (2013). Metode praktis penelitian deskriptif kualitatif. Referensi: Jakarta Selatan

Walsh, S. (2011). Exploring classroom discourse: Language in action. New York: Routledge.

Woofit, R. (2005). Conversation analysis and discourse analysis: A comparative and critical introduction. London: SAGE Publications Ltd. 